\title{
Correlation of Maternal Anemia with Sonographic Placental Thickness
}

\author{
Mehreen Muntaha ${ }^{1}$, Mahjabeen Liaqat ${ }^{1} \quad$ Dr Muhammad Uzair $^{1} \quad$ Mehreen Fatima $^{1}$ \\ Dr Ghulam Muhammad ${ }^{2} \quad$ Sheza Waseem ${ }^{2}$ Dr Muhammad Asif ${ }^{2} \quad$ Kiran Tahir $^{3}$ \\ 1.University Institute of Radiological Sciences and Medical Imaging Technologies, Faculty of Allied Health \\ Sciences, University of Lahore, Lahore, Pakistan \\ 2.The University of Lahore
}

\section{Background:}

Anemia is a condition in which hemoglobin $(\mathrm{Hb})$ concentration and/or red blood cell (RBC) numbers are lower than normal and insufficient to meet an individual's physiological needs, it affects roughly one-third of the world's population.Objective: To correlate the maternal anemia with placental thickness ultrasonographically.Methodology: Toshiba Nemio17 with Convex array transducer 3-5 MHz frequency was used. Patient were in spine position. Measurements of placental thickness were performed in the mid portion of the placenta, perpendicular to its long axis. The study was conducted at Gillani Ultrasound Centre and Mansoorah Teaching Hospital Lahore. Data of 110 patients was collected through cross-sectional, analytical study. Convenient Sampling Technique was used to analyze data. Statistical software for social sciences (SPSS version 22.0) is used for the analysis of data.Results: Out of 110 patients $44.5 \%$ patients were in $2^{\text {nd }}$ trimester and $55.5 \%$ patients were in their $3^{\text {rd }}$ trimester. In our study $26.4 \%$ patients had normal hemoglobin, $43.6 \%$ patients were diagnosed with moderate anemia and $30 \%$ patients were diagnosed with mild anemia. Hemoglobin rates varied between $7 \mathrm{~g} / \mathrm{dL}$ to $15.40 \mathrm{~g} / \mathrm{dL}$. Placental thickness varied between $10.50 \mathrm{~mm}$ and to $56.50 \mathrm{~mm}$. 9 patients had normal placental thickness, 89 had thick placenta and 12 had thin placenta. In $2^{\text {nd }}$ trimester minimum placental thickness was noted $15.7 \mathrm{~mm}$ and maximum placental thickness was $47.2 \mathrm{~mm}$. In $3^{\text {rd }}$ trimester minimum placental thickness was noted as $10.5 \mathrm{~mm}$ and maximum thickness $56.5 \mathrm{~mm}$. In normal placental thickness minimum hemoglobin was noted as $7 \mathrm{~g} / \mathrm{dL}$ and maximum was $15.5 \mathrm{~g} / \mathrm{dL}$. In thick placenta minimum hemoglobin noted was; $7.8 \mathrm{~g} / \mathrm{dL}$ and maximum hemoglobin was $15.4 \mathrm{~g} / \mathrm{dL}$. In thin placental thickness minimum hemoglobin was $8.9 \mathrm{~g} / \mathrm{dL}$ and maximum was $11.2 \mathrm{~g} / \mathrm{dl}$. Majority patients came with hemoglobin rates between 8 to $11(\mathrm{~g} / \mathrm{dL})$ and less than 5 patients came with hemoglobin $7 \mathrm{~g} / \mathrm{dL}$. In patients with mild anemia mean placental thickness was $30.57 \mathrm{~mm}$. In patients with moderate anemia had mean placental thickness of $33.72 \mathrm{~mm}$ and in patients with normal anemia had mean placental thickness of $30.39 \mathrm{~mm}$. Out of 110 patients, 29 had no anemia and from these 3 patients were found with normal placental thickness 4 with thick placenta and 2 were with thin. 81 patients who were diagnosed with anemia had normal placental thickness in 6 patients, 65 had thick placenta and 10 patients were found with thick placenta.Conclusion:We concluded that, maternal anemia has adverse effects on placental thickness and gestational age. In the present study we found that morphological and histological changes in placenta of anemic mother is undertaken, to study the effects of anemia on morphology of placenta and fetal outcomes.

Keywords: Ultrasound (US), anemia, placenta, placental thickness

DOI: $10.7176 / \mathrm{JHMN} / 81-02$

Publication date:October $31^{\text {st }} 2020$

\section{INTRODUCTION}

Anemia is a condition in which hemoglobin $(\mathrm{Hb})$ concentration and/or red blood cell (RBC) numbers are lower than normal and insufficient to meet an individual's physiological needs, it affects roughly one-third of the world's population. ${ }^{1}$

Anemia remains a significant health problem globally, accounting for 60,534 deaths and $3.4 \%$ of global disability-adjusted life years (DALYs) in 2010 in women aged 15-49 $\mathrm{y}^{1}$. The majority of DALYs that are due to anemia occur in low-income countries, particularly in South Asia (5.7\% of DALYs in women) and Sub-Saharan Africa (3.9\% of DALYs in women) $)^{2}$. In high-income countries, $16 \%$ of women and $22 \%$ of pregnant women had anemia in $2011^{3}$. Despite achievements in maternal and child health-related programs over the past decade ${ }^{4,5}$, anemia remains a key health problem in pregnant women in low- and middle-income countries ${ }^{2,6,7}$. The principal causes of anemia are poor nutrition (iron, folic acid, and vitamin deficiencies), infectious diseases such as malaria, and untreated genetic hemoglobin disorders ${ }^{6,8}$. Anemia during pregnancy may cause low birth weight, preterm birth, and perinatal, neonatal and maternal mortality ${ }^{9,10}$, although findings on these risks have not been consistent, and systematic reviews are lacking for low- and middle-income countries.

Maternal anemia is associated with increased morbidity and mortality in women and children, poor birth outcomes, decreased work productivity in adults, and impaired cognitive and behavioral development in children $^{11,12}$ 
The placenta is a fetal organ which provides the physiological link between a pregnant woman and the fetus. The placenta is a highly vascularized organ and its main functions are exchange of metabolic and gaseous products between maternal and fetal bloodstreams, and production of hormones ${ }^{13}$.

The placenta develops from the chorionic villi at the implantation site at about the fifth week of gestation and by the ninth or tenth week the diffuse granular echotexture of the placenta is clearly apparent at sonography ${ }^{14}$.

The human placenta is concerned with the exchanges that occur between the maternal and fetal organisms. The placenta acts like a sieve, moving oxygen and nutrients from the mother's body to baby and taking carbon dioxide and waste materials from the baby into mother's body for elimination. ${ }^{7}$ It has two basic components: the maternal and fetal portions. The placenta originates from the fetal portion (Chorion Frondosum) and maternal portion (Endometrium) more specifically from the Decidua Basalis. Placental function begins around the 4th week of pregnancy, with the formation of the first anatomical elements necessary to ensure physiological exchanges ${ }^{15}$.

About $95 \%$ of anemia cases during pregnancy are iron deficiency anemia. The cause is usually (i) Inadequate dietary intake (especially in adolescent girls) (ii) A previous pregnancy ${ }^{16}$. The most recent data for overall prevalence of maternal anemia, estimated was $38.2 \%$. The prevalence of ultrasonographically thick placentas varies from $0.6 \%$ to $7.8 \%{ }^{20}$. The newborns of anemic mothers are shorter and lower body mass, but not poorer vitality index ${ }^{18}$. Ionic iron is the mineral that promotes the formation of new hemoglobin and is the main source of energy and oxygen transportation to the organs of the body. Maternal anemia can develop due to both the unavailability of this element in the extracellular environment for erythropoiesis and the presence of infectious processes, which may influence the metabolism of hemoglobin. In general, the diagnosis of maternal anemia is defined by hemoglobin levels below $11 \mathrm{~g} / \mathrm{dl}^{19}$.

\section{RESULTS}

One hundred and ten patients participated in this study. Among them, the minimum age was 17 and the maximum age was 40 . out of 110 patients 49 were in their $2^{\text {nd }}$ trimester and 61 were in their $3^{\text {rd }}$ trimester. 29 $(26.4 \%)$ patients had normal hemoglobin, 48 (43.6\%) patients were diagnosed with moderate anemia and 33 (30\%) patients were diagnosed with mild anemia, according to table 1 .

Table1: stages of anemia

\begin{tabular}{|l|l|r|r|r|r|}
\hline \multicolumn{7}{|c|}{ Anemia stages } \\
\hline \multirow{3}{*}{ Valid } & Frequency & Percent & Valid Percent & Cumulative Percent \\
\cline { 2 - 6 } & mild & 33 & 30.0 & 30.0 & 30.0 \\
\cline { 2 - 6 } & moderate & 48 & 43.6 & 43.6 & 73.6 \\
\cline { 2 - 6 } & normal & 29 & 26.4 & 26.4 & 100.0 \\
\cline { 2 - 6 } & Total & 110 & 100.0 & 100.0 & \\
\hline
\end{tabular}

In 110 patients hemoglobin rates varied between $7 \mathrm{~g} / \mathrm{dL}$ and $15.40 \mathrm{~g} / \mathrm{dL}$ with mean value $10.5 \mathrm{SD} \pm 1.88$.

Minimum placental thickness noted was $10.50 \mathrm{~mm}$ and maximum placental thickness was $56.50 \mathrm{~mm}$, according to table 2. Mean of placental thickness in 110 patients came 31.90 with standard deviation of 8.80.

Table 2: descriptive statistics of placental thickness.

\begin{tabular}{|l|r|r|r|r|r|r|r|}
\hline \multicolumn{9}{|c|}{ Descriptive Statistics } \\
\hline & \multicolumn{1}{|c|}{$\mathrm{N}$} & \multicolumn{1}{|c|}{ Range } & Minimum & Maximum & \multicolumn{2}{|c|}{ Mean } & Std. Deviation \\
\cline { 2 - 8 } & Statistic & Statistic & Statistic & Statistic & Statistic & Std. Error & \multicolumn{1}{c|}{ Statistic } \\
\hline Placental Thickness (mm) & 110 & 46.00 & 10.50 & 56.50 & 31.9018 & .83905 & 8.80002 \\
\hline
\end{tabular}

9 had normal placental thickness, 89 had thick placenta and 12 had thin placenta. In $2^{\text {nd }}$ trimester minimum placental thickness was noted $15.7 \mathrm{~mm}$ and maximum placental thickness was $47.2 \mathrm{~mm}$. In $3^{\text {rd }}$ trimester minimum placental thickness was noted as $10.5 \mathrm{~mm}$ and maximum thickness $56.5 \mathrm{~mm}$.

In patients with normal placental thickness minimum hemoglobin was noted as $7 \mathrm{~g} / \mathrm{dL}$ and maximum was $15.5 \mathrm{~g} / \mathrm{dL}$. In patients with thick placenta minimum hemoglobin noted was; $7.8 \mathrm{~g} / \mathrm{dL}$ and maximum hemoglobin was $15.4 \mathrm{~g} / \mathrm{dL}$. In patients with thin placental thickness minimum hemoglobin was $8.9 \mathrm{~g} / \mathrm{dL}$ and maximum was $11.2 \mathrm{~g} / \mathrm{dl}$, according to table 3 . 
Table 3: correlation between hemoglobin and placental thickness.

\begin{tabular}{|l|r|r|r|r|r|}
\hline \multicolumn{7}{|c|}{ Hemoglobin (g/dL) } \\
\hline Placental thickness (thick/thin/normal) & \multicolumn{1}{|c|}{ Mean } & \multicolumn{1}{c|}{$\mathrm{N}$} & Std. Deviation & Minimum & Maximum \\
\hline normal & 10.8556 & 9 & 2.56569 & 7.00 & 15.20 \\
\hline thick & 10.5843 & 89 & 1.90722 & 7.80 & 15.40 \\
\hline thin & 9.9750 & 12 & .74970 & 8.90 & 11.20 \\
\hline Total & 10.5400 & 110 & 1.87657 & 7.00 & 15.40 \\
\hline
\end{tabular}

Majority patients came with hemoglobin rates between 8 to $11(\mathrm{~g} / \mathrm{dL})$ and less than 5 patients came with hemoglobin $7 \mathrm{~g} / \mathrm{dL}$. In 110 patients; 29 had no anemia and from these 3 patients were found with normal placental thickness 4 with thick placenta and 2 were with thin. 81 patients who were diagnosed with anemia had normal placental thickness in 6 patients, 65 had thick placenta and 10 patients were found with thick placenta, according to table 4 .

Table 4: crosstabulation between anemia and placental thicknes
\begin{tabular}{|l|l|r|r|r|r|}
\hline \multicolumn{6}{|c|}{ Anemia * placental thickness crosstabulation } \\
\hline Count & \multicolumn{3}{|c|}{ Placental Thickness } & \multirow{2}{*}{ Total } \\
\cline { 3 - 6 } & Normal & thick & thin & \\
\hline \multirow{2}{*}{ Anemia } & no & 3 & 24 & 2 & 29 \\
\cline { 2 - 6 } & yes & 6 & 65 & 10 & 81 \\
\hline Total & & 9 & 89 & 12 & 110 \\
\hline
\end{tabular}

\section{DISCUSSION}

One hundred and ten patients participated in this study. Among them, the minimum age was 17 and the maximum age was 40 . The mean of the age came out to be 25.89 and $\mathrm{SD} \pm 4.24$, according to the table 1 and graph 1. In 2013, study done by Smaïla Ouédraogo et al, shows that 941 pregnant women participated in this study ${ }^{8}$.

According to table 2 , out of 110 patients 49 were in their $2^{\text {nd }}$ trimester and 61 were in their $3^{\text {rd }}$ trimester.

Out of 110 patients, 46 babies were in breech position and 64 were in cephalic position, according to table 3 .

According to table 4, 41 patients had anterior placenta, 9 patients had fundo-anterior placenta, 8 patients had fundo posterior placenta, 49 patients had posterior placenta.

In current study, according to table 5; out of one hundred and ten patients $50(45.5 \%)$ were gravida 1,41 $(37.3 \%)$ were gravid 2, $18(16.4 \%)$ were gravid 3 and $1(0.9 \%)$ was gravid 4 . In 2013 , study done by Smaila Ouédraogo et al, shows that $18.9 \%$ patients were 1 gravid and $81.1 \%$ were more than 2 gravid $^{8}$.

According to table 6, parity rate varied patient to patient. $58(52.7 \%)$ females came with their first pregnancy. $35(31.8 \%)$ patients had 1 para and $17(15.5 \%)$ patients had 2 para.

Out of 110 patients, out of 110 patients, $29(26.4 \%)$ patients had normal hemoglobin, $48(43.6 \%)$ patients were diagnosed with moderate anemia and $33(30 \%)$ patients were diagnosed with mild anemia, according to table 7.

According to table 8, in 110 patients hemoglobin rates varied between minimum hemoglobin rate being 7 $\mathrm{g} / \mathrm{dL}$ and maximum rate as $15.40 \mathrm{~g} / \mathrm{dL}$ with mean value $10.5 \mathrm{SD} \pm 1.88$.

According to table 9; minimum hemoglobin in $2^{\text {nd }}$ trimester noted was $8.50 \mathrm{~g} / \mathrm{dL}$ and maximum hemoglobin was $15.20 \mathrm{~g} / \mathrm{dL}$. In $3^{\text {rd }}$ trimester the minimum range of hemoglobin noted was $7.00 \mathrm{~g} / \mathrm{dL}$ and maximum range was $15.40 \mathrm{~g} / \mathrm{dL}$.

In current study; minimum placental thickness noted was $10.50 \mathrm{~mm}$ and maximum placental thickness was $56.50 \mathrm{~mm}$, according to table 10 and graph 2. Mean of placental thickness in 110 patients came 31.90 with standard deviation of 8.80 .

Out of 110 patients came in our hospital, 9 had normal placental thickness, 89 had thick placenta and 12 had thin placenta, according to table 11 .

In $2^{\text {nd }}$ trimester minimum placental thickness was noted $15.7 \mathrm{~mm}$ and maximum placental thickness was $47.2 \mathrm{~mm}$. In $3^{\text {rd }}$ trimester minimum placental thickness was noted as $10.5 \mathrm{~mm}$ and maximum thickness $56.5 \mathrm{~mm}$. mean placental thickness in $3^{\text {rd }}$ trimester noted was $35.0393 \mathrm{~mm}$, according to table 12 and graph 2 . In 2009 , study done by CC Ohagwu et al, the results of their study show that the maximum mean placental thickness of $45.1+-6.4 \mathrm{~mm}$ occurred at $3^{\text {rd }}$ trimester of gestation ${ }^{9}$. Mital P in 2009 studied that, in $2^{\text {nd }}$ trimester mean placental thickness was $15 \mathrm{~mm}$ and in $3^{\text {rd }}$ trimester mean placental thickness was $37.5 \mathrm{~mm}^{22}$. In Sadler TW study done in2006 shows, mean placental thickness at term to be $37.5 \mathrm{~mm}^{21}$. These values in previous studies correlate well with current study.

In current study, in normal placental thickness minimum hemoglobin was noted as $7 \mathrm{~g} / \mathrm{dL}$ and maximum 
was $15.5 \mathrm{~g} / \mathrm{dL}$. In thick placenta minimum hemoglobin noted was; $7.8 \mathrm{~g} / \mathrm{dL}$ and maximum hemoglobin was 15.4 $\mathrm{g} / \mathrm{dL}$. In thin placental thickness minimum hemoglobin was $8.9 \mathrm{~g} / \mathrm{dL}$ and maximum was $11.2 \mathrm{~g} / \mathrm{dl}$, according to table 13 .

According to table 14 and graph 3 , out of 110 patients 49 patients were in $2^{\text {nd }}$ trimester and 61 patients were in their $3^{\text {rd }}$ trimester, with the mean of 25.69 and 26.04 respectively. The minimum age of the patients came in $3^{\text {rd }}$ trimester was 18 and maximum age was 36 . The minimum age of the patients came in $2^{\text {nd }}$ trimester was 17 and maximum age was 40 .

According to graph 4, majority patients came with hemoglobin rates between 8 to $11(\mathrm{~g} / \mathrm{dL})$ and less than 5 patients came with hemoglobin $7 \mathrm{~g} / \mathrm{dL}$.

In patients with mild anemia mean placental thickness was $30.57 \mathrm{~mm}$. In patients with moderate anemia had mean placental thickness of $33.72 \mathrm{~mm}$ and in patients with normal anemia had mean placental thickness of 30.39 $\mathrm{mm}$, according to table 15 .

In 110 patients 29 had no anemia and from these 3 patients were found with normal placental thickness 4 with thick placenta and 2 were with thin. 81 patients who were diagnosed with anemia had normal placental thickness in 6 patients, 65 had thick placenta and 10 patients were found with thick placenta, according to table 16.

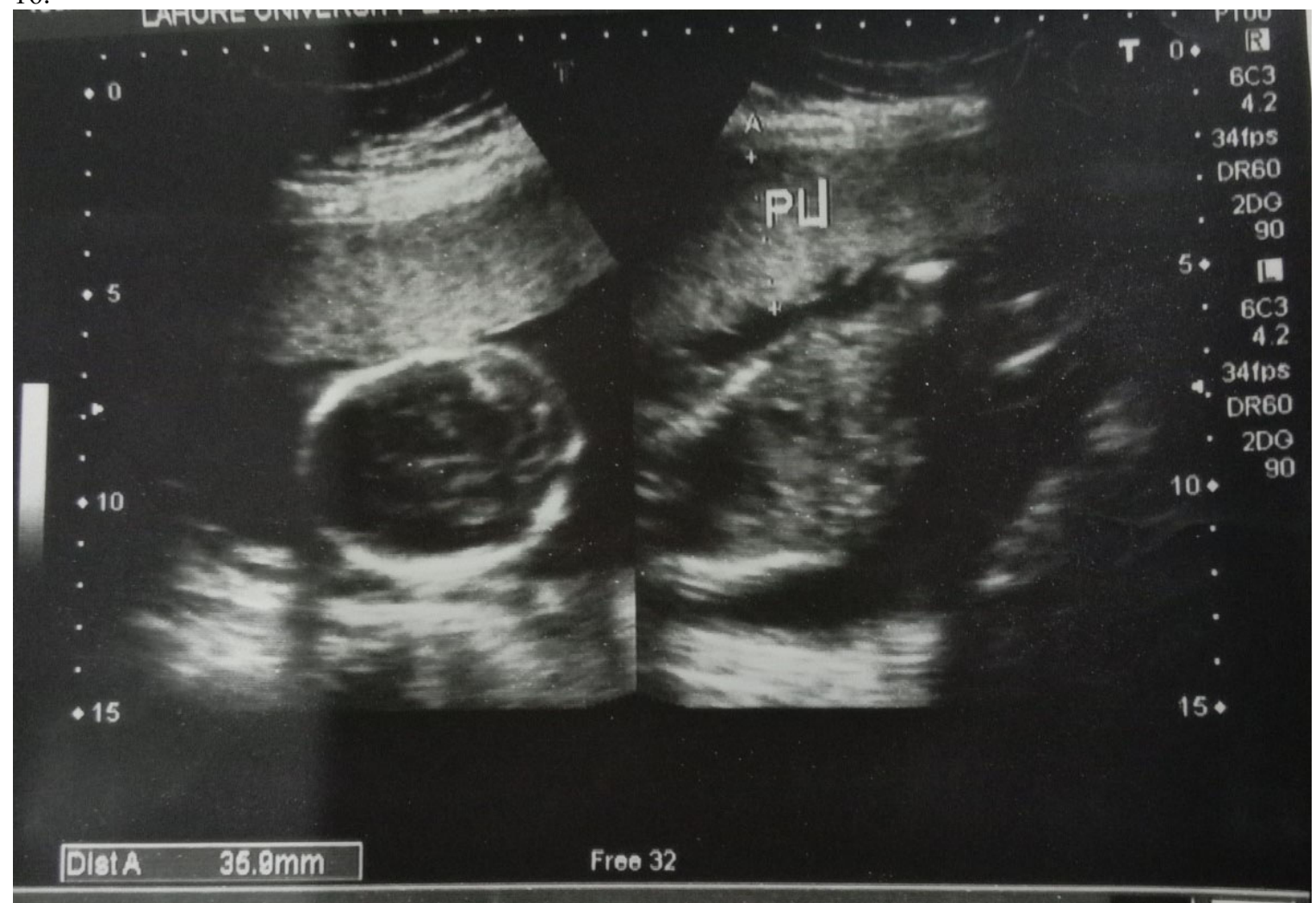

Fig 1: TA gray scale image showing, placental thickness of 36.9mm. 


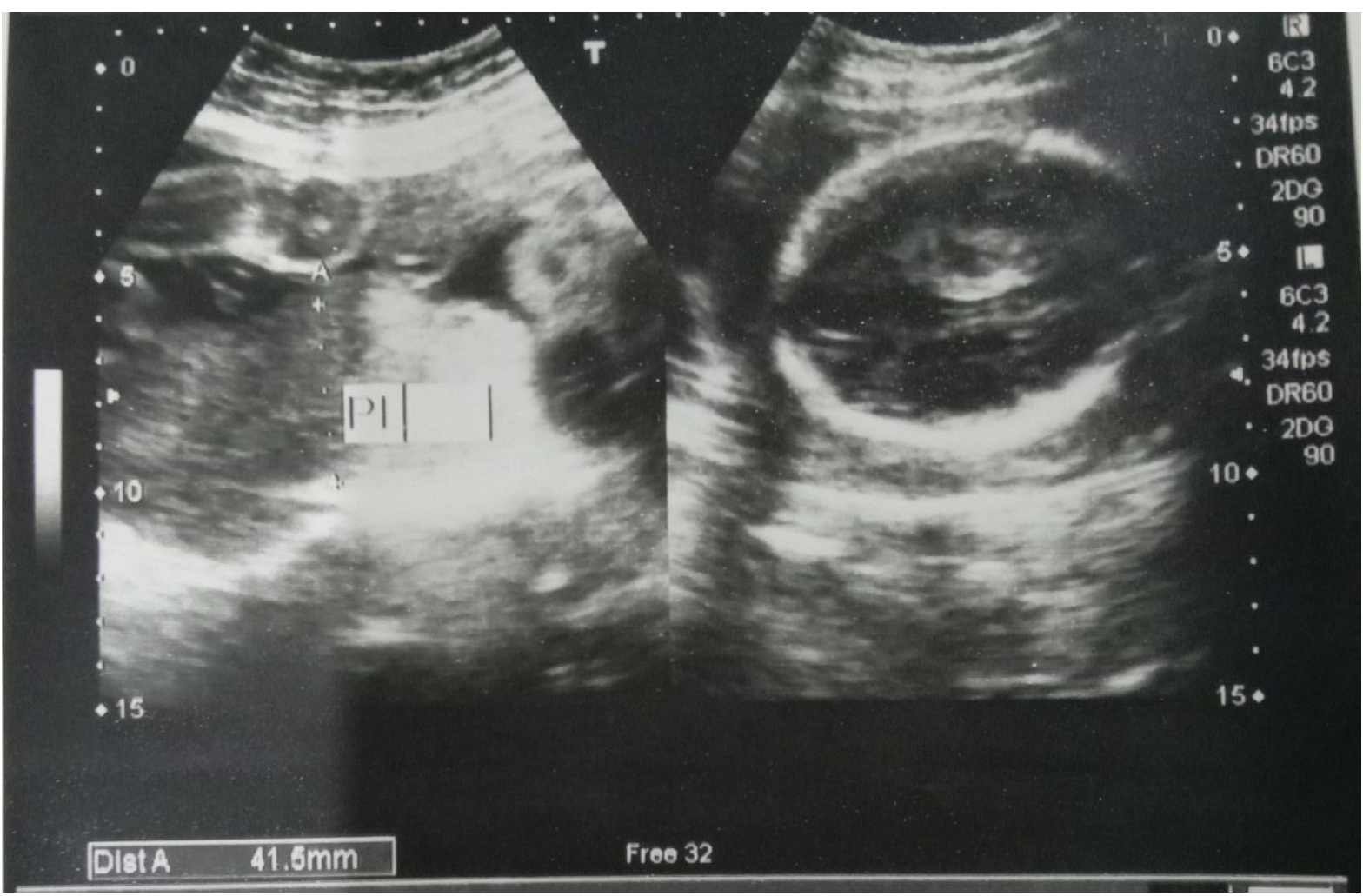

Fig 2: TA gray scale image showing, placental thickness of 41.6mm.

\section{REFERENCES}

1. Institute for Health Metrics and Evaluation HDN, The World Bank The global burden of disease (GBD) compare [Internet]. 2013 ed. Seattle, WA: IHME, 2013

2. Institute for Health Metrics and Evaluation HDN, The World Bank The global burden of disease (GBD) compare [Internet]. 2013 ed. Seattle, WA: IHME, 2013

3. Stevens GA, Finucane MM, De-Regil LM, Paciorek CJ, Flaxman SR, Branca F, Peña-Rosas JP, Bhutta ZA, Ezzati M, Nutrition Impact Model Study Group. Global, regional, and national trends in haemoglobin concentration and prevalence of total and severe anaemia in children and pregnant and non-pregnant women for 1995-2011: a systematic analysis of population-representative data. The Lancet Global Health. 2013 Jul 1;1(1):e16-25

4. Acuin CS, Khor GL, Liabsuetrakul T, Achadi EL, Htay TT, Firestone R, Bhutta ZA. Maternal, neonatal, and child health in southeast Asia: towards greater regional collaboration. The Lancet. 2011 Feb 5;377(9764):516-25.

5. Chowdhury AM, Bhuiya A, Chowdhury ME, Rasheed S, Hussain Z, Chen LC. The Bangladesh paradox: exceptional health achievement despite economic poverty. The Lancet. 2013 Nov 23;382(9906):1734-45.

6. Black RE, Victora CG, Walker SP, Bhutta ZA, Christian P, De Onis M, Ezzati M, Grantham-McGregor S, Katz J, Martorell R, Uauy R. Maternal and child undernutrition and overweight in low-income and middleincome countries. The lancet. 2013 Aug 3;382(9890):427-51.

7. Branca F, Mahy L, Mustafa TS. The lack of progress in reducing anaemia among women: the inconvenient truth.

8. Ouédraogo S, Koura GK, Bodeau-Livinec F, Accrombessi MM, Massougbodji A, Cot M. Maternal anemia in pregnancy: assessing the effect of routine preventive measures in a malaria-endemic area. The American journal of tropical medicine and hygiene. 2013 Feb 6;88(2):292-300.

9. Haider BA, Olofin I, Wang M, Spiegelman D, Ezzati M, Fawzi WW. Anaemia, prenatal iron use, and risk of adverse pregnancy outcomes: systematic review and meta-analysis. Bmj. 2013 Jun 21;346:f3443.

10. Rasmussen KM. Is there a causal relationship between iron deficiency or iron-deficiency anemia and weight at birth, length of gestation and perinatal mortality?. The Journal of nutrition. 2001 Feb 1;131(2):590S-603S.

11. Huang A, Zhang R, Yang Z. Quantitative (stereological) study of placental structures in women with pregnancy iron-deficiency anemia. European Journal of Obstetrics \& Gynecology and Reproductive Biology 2001;97(1):59-64.

12. Suri S, Muttukrishna S, Jauniaux E. 2D-ultrasound and endocrinologic evaluation of placentation in early pregnancy and its relationship to fetal birthweight in normal pregnancies and pre-eclampsia. Placenta 
2013;34(9):745-50

13. Sadler TW. Langman's medical embryology. Lippincott Williams \& Wilkins; 2011 Dec 15.

14. Ohagwu CC, Abu PO, Udoh BE. Placental thickness: A sonographic indicator of gestational age in normal singleton pregnancies in Nigerian women. Internet Journal of Medical Update-EJOURNAL. 2009;4(2).

15. Balla EA, Ahmed MS, Ayad CE, Ahmed AS. Prediction of fetal growth by measuring the placental thickness using ultrasonography. J Gynecol Obstet. 2014 Apr 9;2(2):26-31.

16. Azpurua H, Funai EF, Coraluzzi LM, Doherty LF, Sasson IE, Kliman M, et al. Determination of placental weight using two-dimensional sonography and volumetric mathematic modeling. American journal of perinatology 2010;27(02):151-5.

17. Raio L, Ghezzi F, Cromi A, Nelle M, Dürig P, Schneider H. The thick heterogeneous (jellylike) placenta: a strong predictor of adverse pregnancy outcome. Prenatal Diagnosis: Published in Affiliation With the International Society for Prenatal Diagnosis 2004;24(3):182-8.

18. Raio L, Ghezzi F, Cromi A, Nelle M, Dürig P, Schneider H. Sonographic jelly-like appearance of the placenta: a strong predictor of adverse pregnancy outcome. Prenat Diagn 2004;24:182-8.

19. Lawani LO, Iyoke CA, Onoh RC, Nkwo PO, Ibrahim IA, Ekwedigwe KC, et al. Obstetric benefits of health insurance: A comparative analysis of obstetric indices and outcome of enrollees and non-enrollees in southeast Nigeria. Journal of Obstetrics and Gynaecology 2016;36(7):946-9.

20. Jauniaux E, Ramsay B, Campbell S. Ultrasonographic investigation of placental morphologic characteristics and size during the second trimester of pregnancy. American journal of obstetrics and gynecology 1994;170(1):130-7.

21. Sadler TW. Langman's medical embryology. Philadelphia: Lippincott Williams \& Wilkins; 2006 Sep 20.

22. Mital P, Hooja N, Mehndiratta K. Placental thickness: a sonographic parameter for estimating gestational age of the fetus. Indian journal of Radiology and Imaging. 2002 Nov 1;12(4):553. 